\title{
Phonetic analogy and schwa deletion in French*
}

\author{
JONATHAN BARNES \\ DARYA KAVITSKAYA \\ University of California, Berkeley Yale University
}

\section{Phonetic analogy}

Phonetic analogy as a diachronic phenomenon has been the subject of no small interest at least since the early part of the last century. Bloomfield (1933: 366), for example, notes the following:

Indeed, when we observe sub-phonemic variants, we sometimes find them distributed among speakers or systematized among forms, quite in the manner of linguistic borrowing and of analogical change.

What is interesting in this for Bloomfield is the fact that analogy in its traditional preserve is held to apply only to elements which are phonemically contrastive in a language. The intuition here seems to derive from the notion of contrastiveness in sound systems as the measure of "linguistic relevance" or "conscious opposition", with all that is noncontrastive or subphonemic pertaining only to a lower, more mechanical level of linguistic realization. As such, changes at the level of subphonemic detail are better expected in, for example, the phonetic drift of the neogrammarians than in so rational a process as analogy.

In more recent years, the issue of phonetic or subphonemic analogy has entered the debate surrounding the nature of the phonetics-phonology interface in synchrony as well. Steriade (2000: 332) defines it in this context thus:

... Some processes located in the 'phonetic implementation component' are qualitatively the same as the ones classified as phonological. Phonetic analogy is qualitatively the same process as cyclicity, the paradigmatic extension of contrastive properties.

The problem is essentially the same as before: in the classic Lexical Phonology model of cyclicity, only lexical processes are held to be cyclic. Postlexical processes, operating on elements of subphonemic detail, should not display this characteristic. If it can be shown that they in fact do, this would be a challenge not

\footnotetext{
" We owe much gratitude to the audience of the Fall 2001 Phonology Forum at UCB, and particularly to Andrew Garrett for discussion and inspiration. Many thanks are due to Louis Goldstein, Khalil Iskarous, Doug Whalen and Vladimir Rybin for encouragement, advice and technical assistance.
} 


\section{JONATHAN BARNES AND DARYA KAVITSKAYA}

only to the division of processes into lexical and postlexical, but also to the notion of any meaningful split between phonology and phonetics.

An illustrative example of the putative workings of subphonemic analogy is the familiar English vowel duration before flap problem shown in (1).

(1) Vowel duration before flap

$$
\begin{aligned}
& \text { a. rate raid b. rated raided } \\
& \text { [rějt] [rējd] [rějrəd] [rējrəd] }
\end{aligned}
$$

Earlier held to be a product of rule-ordering, the difference in vowel duration in the two suffixed forms could be ascribed to the operation of phonetic analogy. In the unsuffixed 'rate' and 'raid', the duration of the vowels is determined in part by the identity of the following consonant; before the voiceless $/ t /$, the vowel is phonetically shorter than the vowel before the voiced $/ \mathrm{d} /{ }^{1}$ Upon the addition of the suffix, the voicing distinction in the obstruents is neutralized, both now being realized as $/ \mathrm{r} /$. The difference in duration of the preceding vowels, however, remains, held over, as it were, from the unsuffixed forms. This durational difference can no longer be attributed to the phonetic influence of the following stops; it must therefore be the result of analogical extension through the paradigm of certain phonetic characteristics of the base form.

In the remaining sections of this paper, we discuss one potential instance of subphonemic analogy proposed recently by Steriade (2000), schwa deletion in French. Section 2 describes the facts of the case, and Steriade's experimental results and analysis. In section 3 we present the results of our own experiment, designed to test the veracity of the claim for subphonemic analogy in French schwa deletion. General discussion of the issue follows in section 4, and we conclude in 5 .

\section{French schwa deletion as phonetic analogy}

Schwa deletion in French has received voluminous attention in the phonological literature (e.g., Anderson 1982, Dell 1973, Rialland 1986, Tranel 1981, 1995, 1998, among others). Many researchers have been concerned with the correct division of instances of deleting schwa into separate types or rules. We follow Steriade here in discussing only one of these types, the so-called Optional Schwa Deletion exemplified in (2) and characterized in (3).

$$
\begin{array}{ll}
\text { a. pas de role } & {[\text { pa d] Dol] }} \\
\text { b. pas d'role } & {[\text { pa d Dol] }}
\end{array}
$$

(3) Optional schwa deletion: (V)\#C_.C

\footnotetext{
${ }^{1}$ A common (if not universal) pattern cross-linguistically. The effect is exaggerated in English, making plausible the claim that the difference here is just as phonological as the voicing distinction itself.
} 
In question is the optional deletion of schwa following a single postboundary consonant after a vowel or pause. ${ }^{2}$ This yields the competing forms [pa $\mathrm{d}$ [ $\mathrm{Col}$ ] and [pa d [ol], the second being favored in casual speech.

Rialland (1986) observed a curious fact concerning certain instances of deletion of French schwa. Specifically, she noted that the preceding consonant, in nonpostpausal contexts ostensibly resyllabified as a coda, nonetheless appears in spectrograms to retain much of the phonetic character of its corresponding onset variant, and not to lengthen the preceding vowel, as it would be expected to do were it in fact in the coda.

These facts lead Rialland to posit that while the schwa itself is deleted, the syllabic nucleus it projected is nonetheless retained in the representation. Because of this, the preceding consonant is never in fact resyllabified, continuing instead to occupy the onset of its original syllable, the nucleus of which is now "empty". This is shown in (4a) and (4b) below.

(4) a.

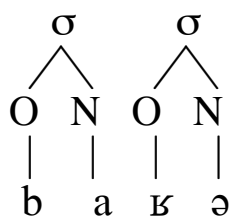<smiles>CNCOCCOC(=O)OC</smiles>

bas retrouvé

b.

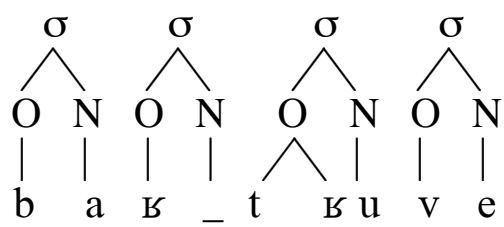

bas r'trouvé

Building on Rialland's work, Fougeron and Steriade set out to confirm experimentally the phonetic peculiarities found in the neighborhood of a deleted schwa. To this end they take minimally-differing phrases from Rialland such as those shown in (5) as tokens for an electropalatographic study. The phrase in token (5a) 'pas de role' contains a schwa optionally subject to deletion by the rules discussed above. (5b) is the same phrase with the schwa now deleted. (5c) contains the same segmental sequence as $(5 \mathrm{~b})$, but with no underlying schwa. Here the two consonants in question are part of a single complex onset. (5d) again contains no underlying schwa, but the d- $\square$ sequence now occurs across a word boundary.

(5) a. pas de role [pa d [ [ol]

b. pas d'role [pa d Dol]

c. pas drole [pa d[Dol]

d. jade rose [[ad Doz]

\footnotetext{
${ }^{2}$ Essentially the conflation of Dell's rules INI Optional and $\mathrm{VCE}_{1}$ Optional (1973). Whether or not certain internal schwas meet the same description is not at issue here.
} 


\section{JONATHAN BARNES AND DARYA KAVITSKAYA}

The results of this study, shown in (6) (tables reproduced from Fougeron and Steriade 1997), support Rialland's observations. For all parameters measured, forms undergoing schwa deletion patterned consistently with the forms still containing schwa, both of these differing significantly from the forms with underlying consonant sequences. (6a) shows that for both speakers, the amount of linguopalatal contact recorded in the articulation of the /d/ was roughly the same for both "pas de role" and "pas d'role", while "pas drole" and "jade rose" formed another class. (6b) shows the mean duration in ms. of the same occlusion, again with the same grouping of results. (6c) records the frequency of lenition of $/ d$ / in each context. Again, the phrases with underlying schwas pattern together, giving the appearance at least of a /d/ in "pas d'role" which continues to be realized with the phonetic characteristics of its onset allophone, despite the fact that, on the surface at least, the nucleus vowel making this possible is absent. Fougeron and Steriade interpret the lesser linguopalatal contact and greater frequency of lenition of the /d/ in underlying /d- $/$ / sequences as the result of the shorter duration of occlusion of the consonant in both these contexts.

(6) Fougeron and Steriade (1997)
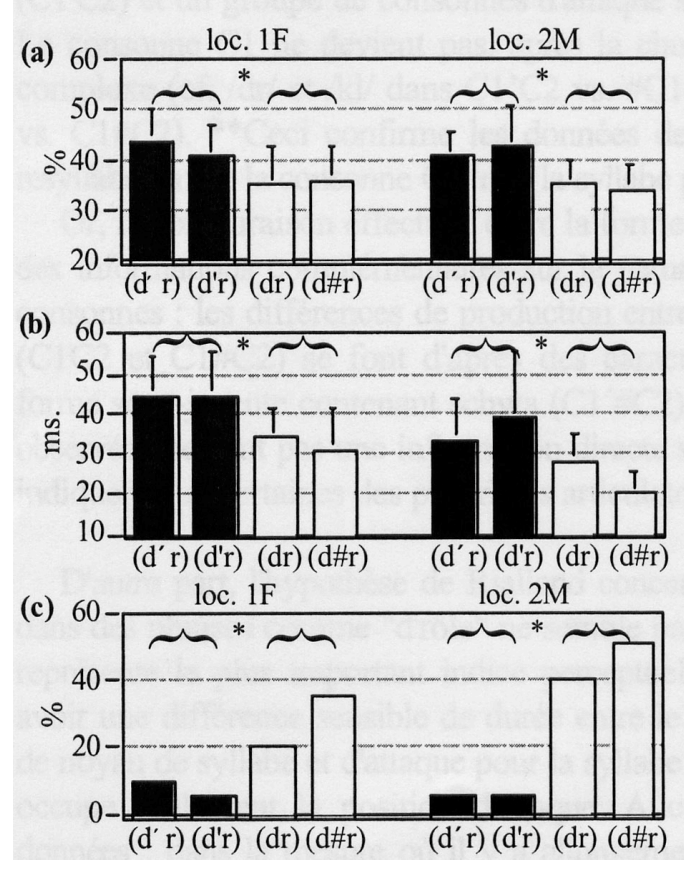

So far then Fougeron and Steriade's results support at least the intuition of Rialland's analysis. But there is a problem. Steriade argues that there is evidence to suggest that the sequence in question does not in fact constitute a syllable on its own in French. In support of this view she brings the following line from a poem by Georges Brassens: 
(7) Il en est de pires il en est d'meilleurs.

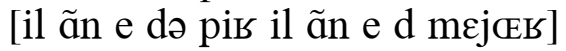

'There are worse and there are better ones.'

On the basis of (7), Steriade (2000: 328) concludes the following:

If d'meilleurs of 'better ones' contains schwa, as $[\mathrm{d} D \mathrm{~m} D \mathrm{j} \square \mathrm{Q}]$, the verse is unacceptably long. Therefore we cannot adopt Rialland's suggestion that the invariant property in $\mathrm{C}(\square) \mathrm{C}$ sequences is the number of syllables: when schwa deletes, the syllable count is correspondingly decreased.

As a solution to this problem, Steriade proposes that the source of the phonetic effects surrounding the deletion of schwa not surface syllable structure at all, but rather, an instance of subphonemic analogy. Under this interpretation, the schwa deletes in its entirety phonologically, while the durational characteristics of surrounding consonants are inherited from the related utterance without schwa deletion. Steriade formalizes this process as a synchronic Paradigm Uniformity effect. The specific constraint she devises is shown in (8).

(8) Paradigm Uniformity (Left: Duration)

If two consonants, $\mathrm{C}$ and $\mathrm{C}^{\prime}$ stand in correspondence and $\mathrm{C}$ is morpheme-initial in the careful pronunciation of the relevant morpheme, $C^{\prime}$ is durationally equivalent to $\mathrm{C}$.

In other words, morpheme-initial consonants in paradigmatically-related forms are required to have the same phonetic durations, even if their immediate phonetic environment might warrant otherwise. This constraint differs in one fairly obvious and significant way from more familiar Faithfulness constraints of OT Correspondence Theory (McCarthy and Prince 1995): Here, rather than the usual correspondence relationship between segments (as in Max and Dep constraints) or abstract phonological features (as in Ident constraints), Steriade's proposal requires correspondence between real-time physical characteristics of the realizations of related Output forms. This proposal constitutes part of a larger research program questioning the reality of the theoretical distinction between phonetic and phonological representation.

\section{Experiment: lip rounding and schwa in French}

In order to test the validity of Steriade's Paradigm Uniformity hypothesis, we designed an experiment, taking advantage of one particular phonetic characteristic of schwa in French. Specifically, French schwa, when realized, is produced with significant rounding of the lips. The question our experiment sets out to answer is this: while deleted schwa certainly seems inaudible, is it in fact dispatched in its entirety, or is any of that rounding gesture retained?

\subsection{Methodology}

For this experiment, we videotaped a native speaker of French producing tokens of the three utterances shown in (9). 


\section{JONATHAN BARNES AND DARYA KAVITSKAYA}

(9) full schwa: Il était bien plus p'tit que Lannes.

deleted schwa: Il était bien plus p'tit qu'la femelle.

no schwa: Ce n'était qu'un tout p'tit clavecin.

These particular sentences are taken directly from Fougeron and Steriade (1997). Tokens were repeated 5 times in random order, for a total of 15 repetitions. The resulting video was subsequently digitize using MyTV $^{\mathrm{tm}}$ digital video software from Eskape Labs. QuickTimePro was used for analyzing the video and selecting the individual frames exhibiting a maximum of lip rounding for each context. These frames were then excised from the video, and degree of lip rounding in each still was measured using NIH Image (by Wayne Rasband, National Institute of Health).

The phonetic literature contains numerous potential strategies for the quantification of degree of lip rounding, such as measurement of lip protrusion, aperture and width of opening. For this experiment, we use the measuring technique proposed by Goldstein (1991), which argues that the most reliable correlate of degree of roundedness for vowels is in fact the side contact of the lips. This is illustrated in Goldstein's figures, reproduced in (10).

(10) Side contact of the lips as the primary articulatory correlate of rounding

a.

b.
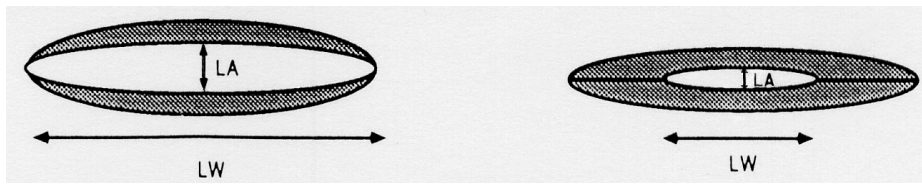

In these figures, (10a) representing an unrounded articulation and (10b) a rounded one, vertical and horizontal arrows indicate dimensions of lip aperture and lip width. Goldstein's measure of side contact refers to the portions of the lip width dimension in which there is contact between the upper and lower lips.

In order to obtain measurements of side contact from our video stills, it was necessary first to set a scale by which NIH Image would establish a correspondence between some unit of distance and the number of pixels between any two points in a given frame. To this end we shot several seconds of the initial video with a measuring tape positioned immediately adjacent to the subject's lips at the appropriate depth in the scene. NIH Image was then able to calculate distances marked off in our stills in millimeters.

\subsection{Results}

The stills shown in (11-13) contain lip rounding maxima for the relevant portions of the three utterance-types in question (full schwa, deleted schwa, and no schwa). The results of our study are evident here upon even a visual inspection: unsurprisingly, the phrases with a fully realized schwa show the most liprounding, and the phrases with no schwa show the least. The phrases with a deleted schwa, however, form a middle category, in which some rounding is 


\section{Phonetic Analogy and Schwa Deletion in French}

present, but not as much as if there would be for a fully realized schwa. The graphs in (14) provide the numbers.

(11) Full schwa: [k] la]

Il était bien plus p'tit que Lannes.

Il était bien plus p'tit que la femelle.

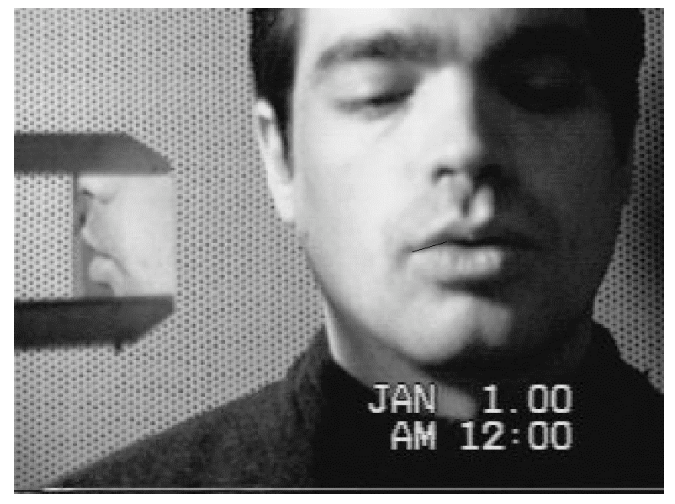

(12) Deleted Schwa: [k_la]

(13) NoSchwa: [kla]

Il était bien plus p'tit qu'la femelle. Ce n'était qu'un tout p'tit clavecin.

Il était bien plus p'tit qu'la table. J'ai vu beaucoup de flics là-bas.

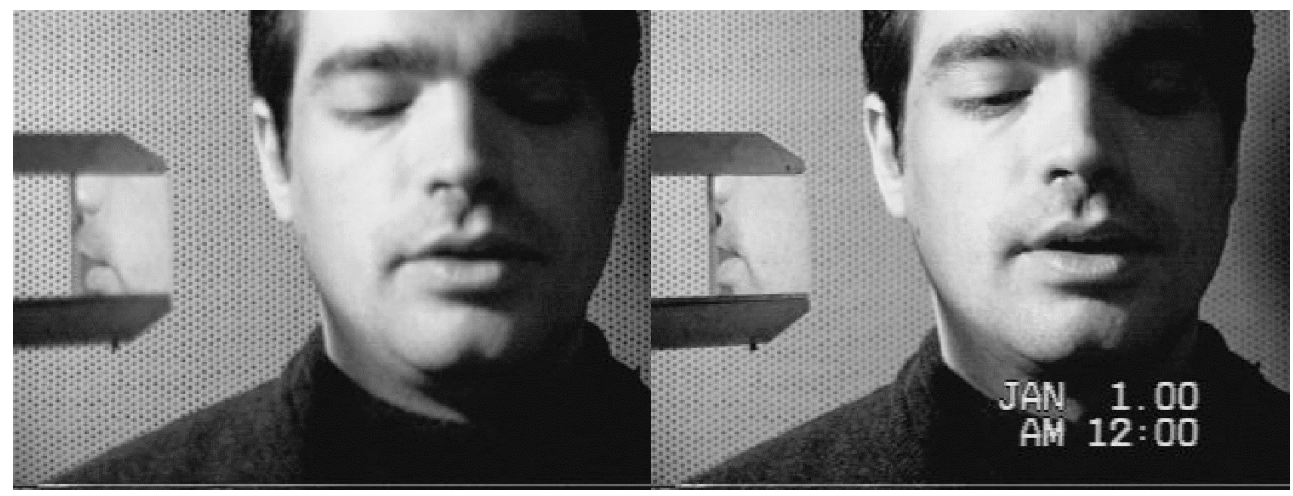

While the size of the sample here makes statistical analysis essentially beside the point, the patterning of the results into three completely non-overlapping classes, each with a small standard deviation is suggestive indeed. It is now necessary on the basis of these results to conduct an expanded version of this study to confirm the pattern emerging here. 


\section{JONATHAN BARNES AND DARYA KAVITSKAYA}

(14) Side contact of lips in mm for three contexts

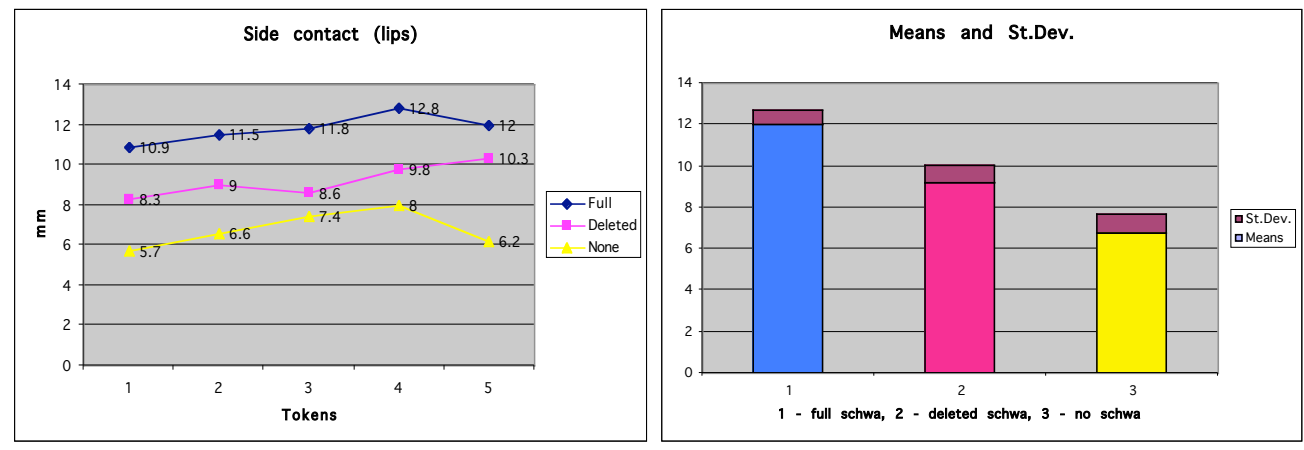

\section{Discussion}

Our results indicate that schwa is not in fact deleted, insofar as some of its component gestures remain articulated. Instead, what we have in French schwa deletion is another instance of articulatory overlap producing the appearance of categorical deletion, as in the famous "perfect memory" facts of Browman and Goldstein 1990. In their words, "much coarticulation and allophonic variation occurs as an automatic consequence of overlapping, invariant underlying gestures" (Browman and Goldstein 1990). As rate of speech increases, so does the overlap of neighboring gestures. In fast speech, then, the inherently short schwa in the French examples above is overlapped completely by surrounding consonants. The gestures comprising schwa may remain (at least in some reduced-magnitude variant), but the schwa itself becomes inaudible. Optional schwa deletion is thus not categorical deletion at all, but rather the result of a gradient process reorganizing the phasing of the consonant gestures of the string relative to those of the nuclear schwa. Under this account, paradigm uniformity is extraneous here.

Steriade's Paradigm Uniformity analysis of French relies on categorical deletion of schwa (with concomitant less of syllabicity), together with analogical extension of one particular phonetic characteristic from a related form. To extend this account in light of our results, additional copresent phonetic analogies could be posited, one for each feature of schwa ultimately located in the deletion environment. For example, Smorodinsky (1986) shows that vertical displacement of the tongue dorsum is significantly different in deleted schwa contexts in French than in comparable consonant clusters. Minimally this adds to the PU account constraints establishing correspondences for not only rounding, but tongue dorsum position as well.

The PU account now says, in essence, apply categorical phonological deletion of schwa, and then restore multiple phonetic features associated with its presence through a list of paradigm uniformity constraints referring to a related utterance of the same string without schwa deletion. The PU account thus casts the facts of schwa deletion as the accidental product of a particular ranking of a list of PU constraints. The prediction is that rerankings could produce the analogical retention of any one of the phonetic characteristics associated with schwa, or indeed any arbitrary constellation thereof. Our account, by contrast, sees here only 
the effect of a single phonological process, a specific rephasing of gestures accompanying casual speech.

Finally, we are left with the problem of the syllabification of sequences with deleted schwa, as exemplified by Steriade's verse from Brassens above. Steriade asserts that for a syllable to scan in French verse, it must have an audible nucleus. Our schwa is present articulatorily, but inaudible. It is therefore passed over for purposes of metrification. The process of extracting firm generalizations about phonological syllabification norms from poetry, however, is far from simple. As Trubetzkoy himself notes, "any metrics is of course violence" (letter to Jakobson, 20 December, 1922 [2001]). Consider, for example, the following quatrains from John Donne. For the first line of the poem in (15) to scan as tetrameter, it is necessary that the words "heaven's influence" contain only three syllables. Likewise, for the first line of the poem in (16) to scan as pentameter, "ignorant" must be disyllabic and "the experienced" must have only three syllables. Leaving aside the question of whether such a parsing of "ignorant" implies the acceptability of $/ \mathrm{nr} /$ onset clusters, we are still left to wonder just how much the possibility of metrifications such as Donne's actually tells us about the syllabification norms of $17^{\text {th }}$ century English.

Donne's tetrameter

On man heaven's influence works not so,

But that it first imprints the air,

So soul into the soul may flow,

Though it to body first repair.

(The Ecstasy, lines 57-60)

[on . man][heaven'. s in][fluence . works][not . so]

[but . that][it . first][im . prints][the . air]

[so . soul][in . to][the . soul][may . flow]

[though . it][to . bo][dy . first][re . pair]

(16) Donne's pentameter

Those wars the ignorant, these th' experienced love,

There we are always under, here above.

There engines far off breed a just true fear,

Near thrusts, pikes, stabs, yea bullets hurt not here.

(Love's War, lines 35-38)

[those . wars][the . ig][norant . these] [th' ex . per][ienced . love],

[there . we] [are . al][ways . un][der . here][a . bove]

[there . en][gines . far] [off . breed][a . just][true . fear]

[near . thrusts][pikes . stabs][yea . bul][lets . hurt][not . here] 


\section{JONATHAN BARNES AND DARYA KAVITSKAYA}

\section{Conclusions}

French schwa deletion is not an instance of phonetic analogy. Rather, gradient reorganization of gestures in a manner familiar from the literature on Articulatory Phonology is enough to account for the facts of this case. The gestural reduction account assumes only the existence of gradient phonological processes capable of targeting a single dimension of the realization of a string. In the case of French schwa, at issue is the phasing of consonant gestures relative to one another. Other phonetic effects associated with this so-called Schwa Deletion (such as the decreased magnitude of the rounding gesture) result directly from accomodations related to this rephasing. Whereas the Paradigm Uniformity approach posits first categorical deletion of schwa and then subsequent reintroduction of phonetic features such as the duration of the preceding consonant, in our account these phonetic features are never altered to begin with. Instead of the sum effect of an arbitrarily large set of analogical repairs to the site of an overzealous deletion, we see the result of a unitary phonological process. 
Phonetic Analogy and Schwa Deletion in French

\section{References}

Anderson, Stephen R. 1982. The analysis of French shwa: or how to get something for nothing. Language 58: 534-573.

Bloomfield, Leonard. 1933. Language. New York: Henry Holt \& Co.

Browman, C.P. and L. Goldstein. 1990. Tiers in Articulatory Phonology with some implications for casual speech. Papers in Laboratory Phonology I: Between the grammar and physics of speech, ed. by J. Kingston and M.E. Beckman. Cambridge: Cambridge University Press, 341-376.

Dell, François. 1973. Les règles et les sons. Paris: Hermann.

Donne, John. 1971. In A.J. Smith, ed., The Complete English Poems. London: Penguin Books, Ltd.

Fougeron, Cecile, and Donca Steriade. 1997. Does deletion of French schwa lead to neutralization of lexical distinctions? In Proceedings of Eurospeech 97, Vol. 2, 943-946.

Goldstein, Louis. 1991. Lip rounding as side contact. Proceedings of the XIIth International Congress of Phonetic Sciences. Université de Provence, 1: 97101.

Kiparsky, Paul. 1985. Some consequences of Lexical Phonology. Phonology Yearbook 2, 85-138.

McCarthy, John J. and Alan S. Prince. 1995. Faithfulness and reduplicative identity. Unpublished manuscript. University of Massachusetts, Amherst and Rutgers University.

Rialland, A. 1986. Schwa et syllabes en Français. In L. Wetzels and E. Sezer (eds.) Studies in Compensatory Lengthening. Dordrecht: Foris.

Smorodinsky, Iris. 1996. Schwas in French: an articulatory analysis. Yale University. Ms.

Steriade, Donca. 2000. Paradigm uniformity and the phonetics-phonology boundary. Papers in Laboratory Phonology V: Acquisition and the Lexicon, ed. by Michael B. Broe and Janet B. Pierrehumbert. Cambridge: Cambridge University Press, 313-335.

Tranel, Bernard. 1981. Concreteness in Generative Phonology: Evidence from French. Berkeley: University of California Press.

Tranel, Bernard. 1995. Current issues in French phonology: liaison and position theories. The Handbook of Phonological Theory, ed. by John A. Goldsmith. Oxford: Blackwell Publishers, 798-816.

Tranel, Bernard. 1999. Optional schwa deletion: on syllable economy in French. Formal Perspectives on Romance Linguistics, ed. by J.-Mark Authier, Barbara E. Bullock and Lisa A. Reed. Amsterdam: John Benjamins, 271-288.

Trubetzkoy, N.S. 2001. In Anatoly Liberman, ed., N.S. Trubetzkoy: Studies in General Linguistics and Language Structure. Duke University Press: Durham.

Zsiga, Elizabeth. 1993. Features, Gestures, and the Temporal Aspects of Phonological Organization. Ph.D Dissertation, Yale University.

Jonathan Barnes

jbarnes@socrates.berkeley.edu

Dept. of Linguistics

University of California, Berkeley

1203 Dwinelle Hall

Berkeley, CA 94720
Darya Kavitskaya

darya.kavitskaya@yale.edu

Dept. of Linguistics

Yale University

P.O. Box 208366

New Haven, CT 06511 